\section{Response to: 'Achieving lupus low disease activity and remission states under belimumab in refractory systemic lupuserythematosus: time and organ involvement matter' by Sbeih et al}

We thank Sbeih et al for their interest in our work. In their correspondence, they show longer time taken to achieve the Lupus Low Disease Activity State (LLDAS) and 'remission' than the Systemic Lupus Erythematosus Responder Index-4 (SRI-4) endpoint in a case series of 50 patients with SLE and active disease treated with intravenous belimumab $10 \mathrm{mg} / \mathrm{kg} .{ }^{1}$ Sbeih et al state that the analyses we undertook in the study by Oon et $a l,{ }^{2}$ which was a post hoc evaluation of BLISS-52 and BLISS-76 trials for the LLDAS endpoint, 'lack data on the time needed to achieve LLDAS...'. However, this is not correct. In supplementary figure 1A) of the publication by Oon et al, we show a longer time taken to achieve LLDAS than SRI-4 in the belimumab $10 \mathrm{mg} / \mathrm{kg}$ arm, with the difference between drug and placebo first reaching statistical significance at week 52 for LLDAS and as early as week 24 for SRI-4 in the BLISS-52 trial. In the BLISS-76 trial, the difference between treatment (belimumab $10 \mathrm{mg} / \mathrm{kg}$ ) and placebo arms reached statistical significance for both LLDAS and SRI-4 endpoints at week 52 and not before.

We note the higher frequency of attainment of LLDAS in the study by Sbeih et al than in our study by Oon et al. Notwithstanding the different population and study design, we also wonder how the LLDAS criteria were applied by Sbeih et al. As noted by Parodis and Nikpour, subtle differences in assessment of LLDAS criteria, for example, the determination of 'no new activity' in Criterion 2, may alter the overall assessment of LLDAS. $^{3}$

Through Kaplan-Meier analysis, Sbeih et al show faster control of articular activity than cutaneous activity. This was not an analysis included on our publication by Oon et al but could be the subject of further post hoc analyses of the BLISS-52 and BLISS-76 datasets.

Finally, in the study by Oon et al, we did not evaluate the attainment of remission in the BLISS-52 and BLISS-76 studies, although we likewise feel that such analyses would be highly informative. Sbeih et al have not specified which one of the eight definitions of remission proposed by the Definition of Remission in Systemic Lupus Erythematosus task force was used in their study. ${ }^{4}$ These definitions differ in inclusion of serological activity and use of immunosuppressives. Having so many definitions of remission presents a challenge in analysis of studies using 'remission' as an endpoint. To enable interpretation of results among studies, it is important to specify the exact definition of remission used.
In summary, both the observational study by Sbeih et al and the post hoc analyses of BLISS clinical trial data by Oon et al show that the attainment of a more stringent endpoint such as LLDAS takes longer to achieve than the SRI-4. This has implications for use of LLDAS as an endpoint in clinical trials and also as a treatment target in clinical practice.

\section{Mandana Nikpour, ${ }^{1,2}$ Molla Huq, ${ }^{1,2}$ Shereen Oon ${ }^{1,2}$}

'Department of Medicine, The University of Melbourne at St Vincent's Hospital, Fitzroy, Victoria, Australia

${ }^{2}$ Department of Rheumatology, The University of Melbourne at St Vincent's Hospital, Fitzroy, Victoria, Australia

Correspondence to Dr Mandana Nikpour, Department of Medicine, University of Melbourne, Fitzroy, VIC 3010, Australia; m.nikpour@unimelb.edu.au

Handling editor Josef $S$ Smolen

Acknowledgements MN holds a National Health and Medical Research Council of Australia (NHMRC) Career Development Fellowship (APP1126370).

Contributors $\mathrm{MN}, \mathrm{MH}$ and $\mathrm{SO}$ contributed conceptually to the drafting of this correspondence response; $\mathrm{MN}$ wrote the response and all authors approved the final document.

Funding The authors have not declared a specific grant for this research from any funding agency in the public, commercial or not-for-profit sectors.

Competing interests None declared.

Patient consent for publication Not required.

Provenance and peer review Commissioned; internally peer reviewed.

(c) Author(s) (or their employer(s)) 2019. No commercial re-use. See rights and permissions. Published by BMJ.

\section{Check for updates}

To cite Nikpour M, Huq M, Oon S. Ann Rheum Dis Epub ahead of print: [please include Day Month Year]. doi:10.1136/annrheumdis-2019-215922

Received 24 June 2019

Accepted 25 June 2019

\section{Linked}

http://dx.doi.org/10.1136/annrheumdis-2019-215732

Ann Rheum Dis 2019;0:1. doi:10.1136/annrheumdis-2019-215922

\section{REFERENCES}

1 Sbeih N, Mathian A, Pineton de Chambrun M, et al. Achieving lupus low disease activity and remission states under belimumab in refractory systemic lupus erythematosus: time and organ involvement matter. Ann Rheum Dis 2019

2 Oon S, Huq M, Golder V, et al. Lupus Low Disease Activity State (LLDAS) discriminates responders in the BLISS-52 and BLISS-76 phase III trials of belimumab in systemic lupus erythematosus. Ann Rheum Dis 2019;78:629-33.

3 Parodis I, Nikpour M. How to use the Lupus Low Disease Activity State (LLDAS) in clinical trials. Ann Rheum Dis 2019:annrheumdis-2019-215650.

4 van Vollenhoven R, Voskuyl A, Bertsias G, et al. A framework for remission in SLE: consensus findings from a large international task force on definitions of remission in SLE (DORIS). Ann Rheum Dis 2017;76:554-61. 